\title{
Green Criminology: cenário das produções científicas
}

Diante das mudanças reflexivas em torno da problemáticas recursos naturais versus dano ambiental, a criminologia emerge nas ciências ambientais percebendo os danos como uma relevante área de investigação criminológica. Este estudo objetivou investigar os estudos em green criminology, em nível global através do levantamento das publicações indexadas à base de dados disponíveis no Portal de Periódicos da Coordenação de Aperfeiçoamento de Pessoal de Nível Superior. A pesquisa possui natureza exploratória quanto aos seus objetivos, e, bibliográfica com relação aos procedimentos utilizados. Adotou-se como estratégia para a coleta de dados critérios bibliométricos para a elaboração de inventário das produções científicas. Os resultados evidenciaram que: as publicações foram disponibilizadas em 13 bases de dados internacionais, localizando-se em até cinco bancos diferentes; artigo foi o documento com maior ocorrência, representando $46 \%$ das publicações, disponíveis em 18 periódicos indexados; três autores perfizeram $55 \%$ do número de publicações, caracterizando-se por autorias múltiplas, o que prediz percepções diversas do objeto de análise; não há entre os autores nenhum pesquisador vinculado direta ou indiretamente a departamento da administração pública dos países; geograficamente as discussões abrangeram pesquisadores de 11 países desenvolvidos; quanto a dinâmica temporal houve crescimento progressivo nas publicações a partir de 2008. Conclui-se que a ausência de estudos em green criminology encontra limites nas questões políticas-geográficas o que inibe a diversidade de percepções espaciais sobre a temática, refletindo no amadurecimento das pesquisas em relação a teoria.

Palavras-chave: Green Criminology; Dano Ambiental; Publicações; Precursores.

\section{Green Criminology: scientific production scenario}

\begin{abstract}
Faced with the reflexive shifts around natural resources versus environmental damage, criminology emerges in the environmental sciences perceiving damages as an important area of criminological investigation. This study aimed to investigate the studies in green criminology, at a global level, through the survey of publications indexed to the database available on the Portal de Periódicos da Coordenação de Aperfeiçoamento de Pessoal de Nível Superior. The research has an exploratory nature in relation to its objectives and, bibliographical in relation to the procedures used. It was adopted as strategy for the collection of data bibliometric criteria for the elaboration of inventory of scientific productions. The results showed that: publications were available in 13 international databases, located in up to five different banks; The article was the most frequent document, representing $46 \%$ of the publications, available in 18 indexed journals; Three authors represented $55 \%$ of the number of publications, being characterized by multiple authorship, which predicts different perceptions of the object of analysis; There is no researcher directly or indirectly linked to the department of public administration of the countries among; Geographically, the discussions involved researchers from 11 developed countries; As for the temporal dynamics, there has been a progressive growth in the publications since 2008. It is concluded that the absence of studies in green criminology finds limits in the political-geographical questions which inhibits the diversity of spatial perceptions on the subject, reflecting in the maturation of the research with respect to the theory.
\end{abstract}

Keywords: Green Criminology; Environmental Damage; Publications; Precursors.

\section{Topic: Legislação e Direito Ambiental}

Reviewed anonymously in the process of blind peer.

Cíntia Rosina Flores

Universidade do Vale do Taquari, Brasil http://lattes.cnpq.br/7655151657670894 http://orcid.org/0000-0002-4384-3097 rosinaflores@gmail.com

\section{Odorico Konrad}

Montanuniversität Leoben, Áustria http://lattes.cnpq.br/9946679953072196 okonrad@univates.br

Josmar Almeida Flores (iD

Universidade do Vale do Taquari, Brasil http://lattes.cnpq.br/7617549273492752 http://orcid.org/0000-0002-4111-4536 josmarflores@gmail.com

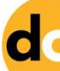

DOI: 10.6008/SPC2179-6858.2017.004.0022
Received: 19/07/2017

Approved: 20/10/2017

\section{Referencing this:}

FLORES, C. R.; KONRAD, O.; FLORES, J. A.. Green Criminology: cenário das produções científicas. Revista Ibero-Americana de Ciências Ambientais, v.8, n.4, p.268-280, 2017. DOI: http://doi.org/10.6008/SPC2179-6858.2017.004.0022 


\section{INTRODUÇÃO}

O cenário ambiental global é permeado por discussões que almejam a proteção ambiental. Tal realidade é refletida nas convenções, tratados e acordos internacionais, que apregoam regras entre os países signatários, visando a conservação dos recursos naturais no processo do desenvolvimento sustentável. Para tanto, a implementação da sustentabilidade perpassa pela observação interdependente e sistêmica de suas dimensões mínimas (ambiental, social e econômica), com vista a uma integração respeitosa/harmônica das características naturais e dos aspectos socioespaciais, ou seja, justiça ambiental (IORIS, 2009; JACOBI et al., 2015; PELLIZZARO et al., 2015)

Contraposto, tem-se na interação sociedade e ambiente à ocorrência de danos ambientais, complexos em sua natureza, vez que não respeitam limites territoriais e produzem efeitos a curto, médio e longo prazo, impactando vítimas de forma direta e indireta. Daí, afirma-se que a degradação ambiental, por vezes, dá-se de forma irreversível e irreparável, perfazendo consequências nefastas para o ambiente e a humanidade. É a permeabilidade das fronteiras contemporâneas, conexas as dimensões transnacionais em níveis econômicos, políticos e sociais (BISSCHOP, 2015; CASTRO et al., 2011).

Leite et al. (2012) denomina de eventos transfronteiriços oriundos de uma sociedade de risco (BECK, 2011), alicerçada no consumo desenfreado, desperdício, ausência de ética para reconhecer limites à exploração dos recursos naturais, falta de investimento em fontes renováveis de energia e descompromisso com a educação ambiental. O combate eficiente aos danos ambientais perpassa, obrigatoriamente, pela sua predição, esta alcançada através da sua compreensão (HINOJOSA, 2012). Assim, apenas com o conhecimento dos múltiplos fatores e atores é possível designar ações e procedimentos preventivos ou, ainda, políticas públicas pautadas na governança ambiental (ZHOURI, 2008; PRIEUR, 1996).

Portanto, a problemática da degradação ambiental (alteração adversa do equilíbrio ecológico) necessita ser percebida multidisciplinarmente, através da integração de distintos campos das ciências, possibilitando uma real compreensão das complexas relações inerentes à ocorrência dos danos ambientais (BRASIL, 1981; ELVAN, 2014; MILARÉ, 2013; SÁNCHEZ, 2013).

Nessa perspectiva, que "não há ciência que possa abranger e dominar todas as variáveis ambientais e as relações ecossistêmicas" (VIVEIROS et al., 2015), a criminologia emerge nas ciências ambientais percebendo os danos ambientais como uma relevante área de investigação criminológica (FITZGERALD et al., 2010; HINOJOSA, 2012). A esse fenômeno contemporâneo, consolidado no início da década de 1990, denominou-se green criminology (criminologia verde), tema cada vez mais recorrente, percebido enquanto referência para reflexões sobre os danos, crimes, leis e justiça ambiental (LYNCH, 2013; PUCCI, 2013; SOUTH et al., 2014a).

Diante das mudanças reflexivas em torno da problemática recursos naturais versus dano ambiental, esta pesquisa consiste na investigação dos estudos em green criminology, em nível global através do levantamento das publicações indexadas à base de dados disponíveis em acervo digital. Para tanto, elaborou-se inventário das produções científicas a partir dos subsídios da tipologia científica dos 
estudos reflexivos sobre o tema, autoria dos documentos, vinculação institucional dos pesquisadores, identificação espacial da ocorrência das discussões sobre green criminology no cenário global e delimitação cronológica das publicações, compreendido como marco o ano de 1990, período em que a teoria ganha a nomenclatura usual.

\section{REVISÃO TEÓRICA}

\section{Introdução a green criminology}

Se as discussões acerca da proteção ambiental, bem como edição de normas e regulamentos, emergiram apenas há algumas décadas, mais recente são as altercações acerca da green criminology. 0 marco está no ano de 1990 quando Michael Lynch publicou um manifesto pioneiro, o artigo científico intitulado "The greening of criminology: a perspective on the 1990's.", em edição do The Critical Criminologist, que tinha circulação limitada atingindo principalmente a América do Norte, o que dificultou que pesquisadores de outros países tivessem acesso (BRISMAN et al., 2013; LYNCH, 2013; SOUTH et al., 2014a).

Somente há 17 anos a green criminology propagou-se mais amplamente, através de Piers Beirne e Nigel South ao publicarem, em maio de 1998, uma edição da revista Theoretical Criminology intitulada "o campo verde do estudo da criminologia", inovando as discussões acerca do desenvolvimento teórico da Criminologia Verde e às nossas relações com a natureza, isso foi possível porque tal revista possui escopo amplo e inclusivo, abrangendo a grande diversidade de pensar dentro criminologia (LYNCH, 2013; WYATT et al., 2014).

Em pouco mais de duas décadas, green criminology tornou-se uma nova perspectiva estabelecida no campo criminológico, incorporando uma gama de tópicos e controvérsias que incluem dimensões de gênero, etnia e cultura, dentre outras questões que corroboram no estudo da área criminológica. Assim, fornecendo, para as áreas antigas e novas de investigação, conexões interdisciplinares importantes (SOUTH et al., 2014b; SOUTH et al., 2014a; WHITE, 2013).

Nesse contexto, a green criminology emerge como uma possibilidade tipológica do fenômeno criminológico moderno. Apresentando-se como um estudo ecologicamente sensível e visando proporcionar uma compreensão mais ampla da justiça ambiental, através de conceituações jurídicas e sociais dos danos ambientais, bem como da relação do meio ambiente e a criminalidade, demonstrando conscientização dos impactos humanos negativos sobre o ambiente natural (SOUTH et al., 2014b; SOUTH et al., 2014a).

\section{Bases terminológicas da green criminology}

As peculiaridades desta tipologia criminológica impetram-se também na sua denominação, a qual não é brindada com um consenso uníssono quanto a nomenclatura dessa área, majoritariamente criminólogos empregam o termo Green Criminology, no intuito de delinear o estudo do crime, dos danos e das injustiças conexas com as questões do meio ambiente, entendido aqui em seu conceito quadruplo, qual seja, natural, artificial, cultural e do trabalho, contudo há outras terminologias e abordagens no cenário internacional para tal demandas: Conservation Criminology (Criminologia da Conservação); Eco-crime; Eco- 
global Criminology (Criminologia Eco-mundial); Environmental Criminology (Criminologia Ambiental), conforme apresentado na figura 1 (AMADO, 2013; MILARÉ, 2013; SOUTH, 2014).

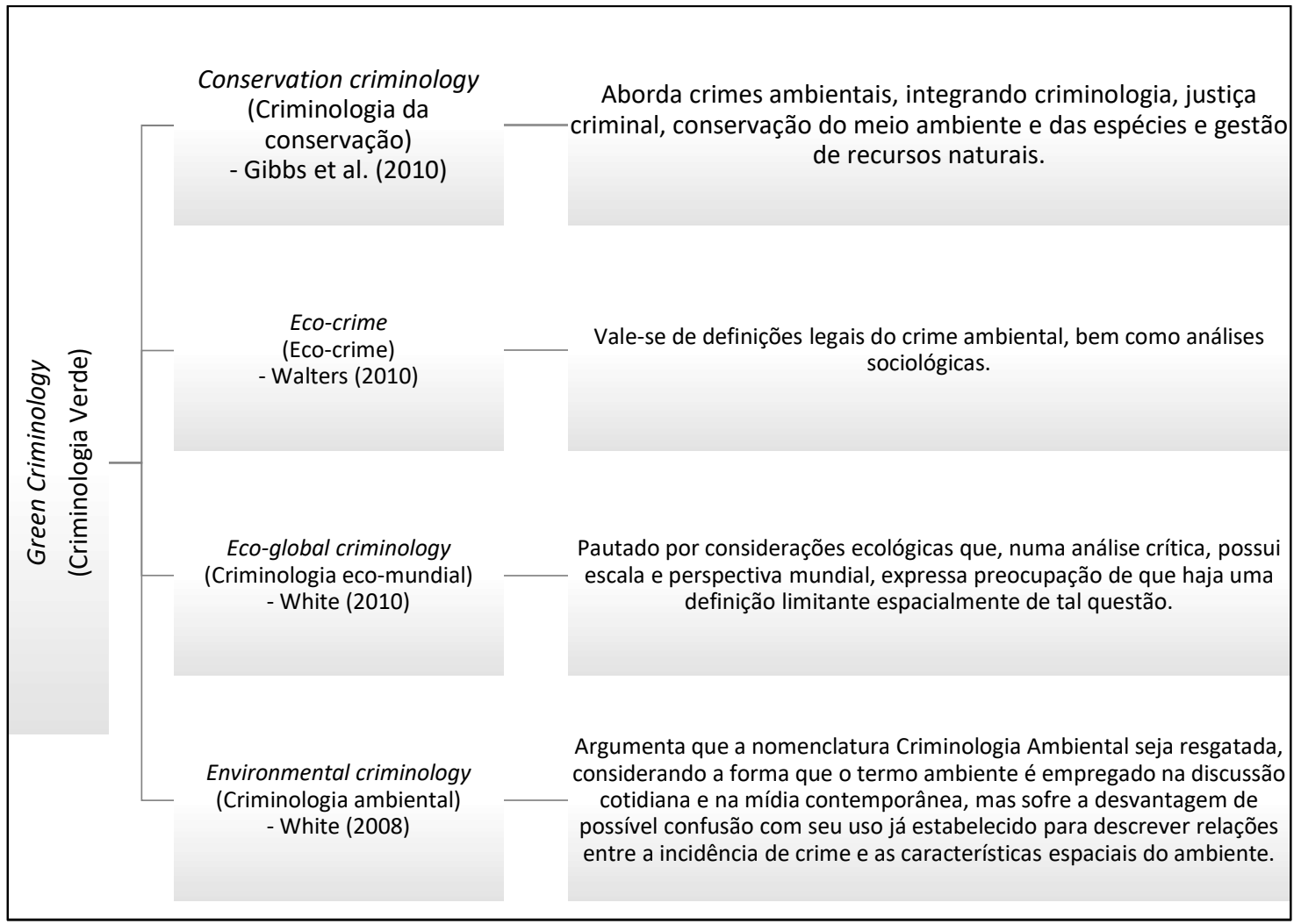

Figura 1: Terminologias da Green Criminology empregadas no cenário internacional.

Fonte: South (2014).

Embora a green criminology possui, no sentido mais amplo possível, seu foco nas questões atinentes ao ambiente, diverge da Criminologia Ambiental, isso porque, apenas à espécie criminológica em estudo na pesquisa, corresponde à análise dos crimes ambientais, assim denominadas em solo pátrio as condutas consideras lesivas ao meio ambiente (FARIA et al., 2012).

Já na Criminologia Ambiental, estuda-se a influência do ambiente sobre o comportamento humano, ou seja, a personalidade antissocial é desenvolvida em múltiplos fatores e aspectos ambientais que o rodeiam, são as consequências de fatores ambientais como: espaço, a estrutura física, calor, frio, ruído, etc. Tal ligação baseia-se na teoria de que pessoas respondem ao ambiente em mudança, assim, as forças externas encorajam os sujeitos a praticar determinadas conduta (HIKAL, 2009; PENTEADO FILHO, 2012; WORTLEY et al., 2011).

Esse entendimento provém da Escola de Chicago, a qual funda-se na afirmação de que os distintos padrões da conduta humana são moldados pelas variáveis do vetor espaço-tempo onde tais condutas ocorrem, isso porque, no início do século XX a cidade de Chicago sofreu alterações com a implantação da industrialização e por conseguinte do aumento populacional que atingiu em 1930 a marca de três milhões de habitantes, todo esse processo levou a problemática do crime, o que culminou em uma investigação para compreender e intervir na ocorrência de tais condutas criminais (AGRA, 2012; PENTEADO FILHO, 2012). 


\section{Abordagem do dano em green criminology}

O espaço para as discussões de danos e crimes ambientais, na literatura criminológica, era insipiente no século passado (LYNCH et al., 2013). A green criminology revoluciona expandido a disciplina para estudar o dano ambiental, a partir do exame das noções de crimes, infrações e condutas prejudiciais ao meio ambiente, analisando o papel em gerar tais impactos negativos não só das sociedades, mas também das corporações e governos ou grandes atores (SOUTH et al., 2014a; WHITE, 2003).

Esses novos parâmetros de analises do dano ambiental advém do entendimento de que a green criminology engloba o estudo teórico e empírico das condutas e ações que impactam prejudicialmente o ambiente, causando o dano. Essas ações são complexas diferenciando-se em crimes ambientais primários e secundários. Os primários são responsáveis pelo impacto direto, categorizando-se de acordo com as condutas danosas contra espécies da fauna e da flora, poluição do ar, desmatamento e deterioração da terra e poluição da água, refletindo a destruição e degradação dos recursos naturais. Já os crimes ambientais secundários dependem de tal destruição e dos esforços realizados para regular ou impedi-los, incluindo as condições que se seguem após o dano ambiental, exemplo disso são os mercados ilegais para alimentos, medicamentos e até mesmo água potável (SOUTH et al., 2013a; SOUTH et al., 2013b; SOUTH et al., 2014a).

Tais danos ambientais são classificados de acordo com sua tipologia em marrom, verde e branco. Marrom, em termos de vida urbana e poluição, verde significando conservação e preocupações da natureza e branco referindo-se ao impacto das novas tecnologias e diversas práticas de laboratório (figura 2) (SOUTH et al., 2014b; SOUTH et al., 2014a; WHITE, 2013).

\begin{tabular}{|c|c|c|}
\hline Marrom & Verde & Branco \\
\hline $\begin{array}{l}\text { Poluição do ar; } \\
\text { Poluição das águas pluviais } \\
\text { urbanas; } \\
\text { Poluição de praias; } \\
\text { Pesticidas; } \\
\text { Derramamentos de óleo; } \\
\text { Poluição de captação de água; } \\
\text { Eliminação dos resíduos } \\
\text { tóxicos/perigosos. }\end{array}$ & $\begin{array}{l}\text { Chuva ácida; } \\
\text { Destruição do habitat; } \\
\text { Perda de animais selvagens; } \\
\text { Exploração de floresta; } \\
\text { Depleção de camada de ozono; } \\
\text { Algas tóxicas; } \\
\text { Espécies invasoras por meio de } \\
\text { transportes humano; } \\
\text { Poluição da água. }\end{array}$ & $\begin{array}{l}\text { Organismos geneticamente } \\
\text { modificados; } \\
\text { Irradiação de alimentos; } \\
\text { Processos in vitro; } \\
\text { Clonagem de tecidos humanos; } \\
\text { Discriminação genética; } \\
\text { Doenças transmissíveis } \\
\text { relacionadas com o meio } \\
\text { ambiente; } \\
\text { Ambientes internos patológicas; } \\
\text { Ensaios em animais e } \\
\text { experimentação - } \\
\text { Nanotecnologias. }\end{array}$ \\
\hline
\end{tabular}

Figura 2: Classificação das questões ambientais de acordo com a tipologia do dano.

Fonte: South et al. (2014); White (2005).

Nesse cenário de especializações criminológicas e heterogeneidade das categorizações dos danos e, por conseguinte, do objeto de estudo da Criminologia Verde, South et al. (2014) subcategoriza este fenômeno em subáreas, propagando que é na diversidade de maneiras de abordagens da questão que encontra-se eficiente instrumento de entendê-la, tais como: criminologia verde radical (radical green criminology); criminologia eco-global (eco-global criminology); criminologia da conservação (conservation criminology); criminologia ambiental (environmental criminology); e criminologia verde construtivista ou 
cultural (constructivist or cultural green criminology).

Observa-se que tais tipologias e classificações ocorrem em consequência da necessidade de compreensão ampla e pormenorizada do crime e dano ambiental, para que então possa-se alcançar a almejada preservação ambiental. Assim, é fato que a green criminology é fundamental na compreensão do crime e dos danos ambientais, sendo a subárea da Criminologia da Conservação que detém o campo preservacionista dos recursos naturais como núcleo imediato, instituindo uma gestão fundamentada em questões criminológicas, na aplicação da legislação ambiental e nas condutas tipificadas como crimes ambientais (SOUTH et al., 2014a).

\section{METODOLOGIA}

O presente estudo possui natureza exploratória quanto aos seus objetivos, e, bibliográfica com relação aos procedimentos utilizados, considerando que o trabalho proposto tem por escopo, investigar os estudos da green criminology em nível global, através de levantamento da produção científica acerca do tema, sem delimitação temporal inicial, tendo como data final 31 de janeiro do ano de 2016.

A estratégia adotada para a coleta de dados assume critérios bibliométricos (FERREIRA, 2010) em relação a elaboração de inventário das produções científicas (DIAS et al., 2015), identificadas a partir do procedimento metodológico desk research, envolvendo o exame de dados secundários das publicações referentes aos estudos em green criminology, em acervo virtual de abrangência internacional.

Considerando a realidade contemporânea da globalização da produção intelectual com a difusão digital de obras literárias (sociedade de informação), consequência do potencial das novas tecnologias em disponibilizar acervos, realizou-se a coleta de dados em periódicos e livros disponibilizados por repositório digital que contemplam bases de dados internacionais.

A terminologia empregada na busca dos dados foi 'green criminology', delimitada tendo por base a utilização dos termos no idioma inglês visando a eliminação de barreiras linguísticas e, portanto, ampliando os resultados, bem como a obtenção de um panorama internacional das discussões sobre a matéria na literatura científica.

\section{Bancos de dados empregados na coleta dos dados}

A coleta de dados realizou-se na biblioteca digital do Portal de Periódicos da Coordenação de Aperfeiçoamento de Pessoal de Nível Superior (CAPES), que contempla acesso a bases de dados nas diversas áreas do conhecimento, incluindo as ciências ambientais, sociais aplicadas e multidisciplinares.

Quanto aos procedimentos para busca e seleção o estudo efetivou-se por meio da string 'green criminology' na opção busca avançada por assunto, utilizando-se os parâmetros restritivos título e assunto da bibliografia com resultados expandidos, o que possibilitou a obtenção de dados mais precisos, resultando em um total 233 publicações de informação científica, dos quais 164 estavam duplicados nas bases de dados, totalizando uma amostra final de 69 publicações. 


\section{Operacionalização dos dados}

Para a análise dos dados e construção do inventário, a amostra foi submetida a análise de publicações quanto as variáveis: Bases de dados - verificação da incidência de publicações por base de dados; Tipologia - estabelecimento da ocorrência dos documentos por formato, com base na tipologia adotada pelo Portal de Periódicos da CAPES; Autoria - consistindo na identificação e classificação dos autores mais produtivos; Vinculação institucional - identificação da instituição a qual o autor encontra-se filiado acadêmica ou cientificamente; Espacialização das publicações - verificação da espacialização geográfica da ocorrência das discussões sobre green criminology no cenário global; e Cronologia das publicações levantamento da dinâmica temporal da ocorrência das publicações, compreendido como marco o ano de 1990.

O inventário dos dados coletados foi tabulado e processado através do software Microsoft Excel. O estudo proposto envolve a utilização de dados secundários, expressos em publicações científicas o que caracteriza a identificação dos autores como de domínio público, destarte as questões éticas encontram-se preservadas.

\section{RESULTADOS E DISCUSSÃO}

As seções seguintes apresentam os principais resultados do estudo bibliográfico, das análises bibliométricas nas publicações disponíveis em acervo virtual que abordam a temática emergente green criminology. A Tabela 1 demonstra que a string "green criminology" vinculou-se a 13 bases de dados no acervo virtual do Portal de Periódicos da CAPES, ao longo de 18 anos. Seis bases possuem percentual de publicações acima de $10 \%$ em relação aos 69 documentos estudados, sendo que a Scopus disponibilizou mais da metade dos mesmos, num total de 41 registros. Na sequência Web of Science 39\%, Cengage Learning, Inc. 23\%, ProQuest LLC All rights reserved 19\%, Springer Science \& Business Media 14\% e SAGE Publications 13\%.

Tabela 1: Publicações da amostra por base de dados.

\begin{tabular}{|c|c|c|c|c|c|c|c|c|c|c|c|c|c|c|}
\hline Bases de Dados & જ్ & ్ㅇ & ஜ̊ & ঠ্ণ & ঠ্ণ & $\stackrel{\infty}{\stackrel{\nu}{~}}$ & 유 & $\begin{array}{l}\circ \\
\text { 궁 } \\
\text { 이 }\end{array}$ & 귱 & 공 & $\stackrel{m}{\stackrel{\sim}{N}}$ & $\underset{\sim}{\stackrel{\sim}{\circ}}$ & $\stackrel{\text { ㅁํㅇ }}{\stackrel{\sim}{N}}$ & $\begin{array}{l}\bar{\pi} \\
\stackrel{0}{0} \\
\bullet\end{array}$ \\
\hline Scopus (Elsevier B.V) & 0 & 1 & 1 & 1 & 1 & 0 & 0 & 1 & 1 & 2 & 16 & 9 & 8 & 41 \\
\hline Web of Science & 0 & 0 & 1 & 1 & 0 & 1 & 3 & 1 & 1 & 1 & 7 & 5 & 6 & 27 \\
\hline Cengage Learning, Inc. & 0 & 0 & 0 & 0 & 0 & 1 & 1 & 1 & 0 & 0 & 3 & 7 & 3 & 16 \\
\hline ProQuest LLC All rights reserved & 1 & 0 & 1 & 1 & 0 & 1 & 2 & 0 & 1 & 1 & 3 & 1 & 1 & 13 \\
\hline Springer Science \& Business Media & 0 & 0 & 0 & 0 & 0 & 0 & 0 & 1 & 1 & 0 & 3 & 3 & 2 & 10 \\
\hline SAGE Publications & 0 & 0 & 0 & 0 & 0 & 0 & 1 & 0 & 0 & 1 & 2 & 0 & 5 & 9 \\
\hline Oxford University Press & 0 & 0 & 0 & 1 & 0 & 1 & 0 & 0 & 0 & 0 & 1 & 1 & 1 & 5 \\
\hline Gale Virtual Reference Library & 0 & 0 & 0 & 0 & 1 & 0 & 0 & 0 & 0 & 0 & 0 & 2 & 0 & 3 \\
\hline Networked Digital Library & 0 & 0 & 0 & 0 & 0 & 1 & 0 & 0 & 0 & 0 & 1 & 0 & 0 & 2 \\
\hline Inderscience Journals & 0 & 0 & 0 & 0 & 0 & 0 & 0 & 1 & 0 & 0 & 0 & 0 & 0 & 1 \\
\hline MEDLINE/PubMed & 0 & 0 & 0 & 0 & 0 & 0 & 0 & 0 & 0 & 0 & 0 & 0 & 1 & 1 \\
\hline Project MUSE & 0 & 0 & 0 & 0 & 0 & 0 & 0 & 0 & 0 & 0 & 0 & 0 & 1 & 1 \\
\hline Sciencedirect & 0 & 0 & 0 & 0 & 0 & 0 & 0 & 0 & 0 & 0 & 0 & 0 & 1 & 1 \\
\hline
\end{tabular}

Os dados evidenciam que as publicações foram disponibilizadas em bases internacionais diversas, localizando-se em até cinco bancos diferentes, demonstrando maior acessibilidade aos pesquisadores, estudantes e profissionais atuantes na área. Considerando que tais acervos digitais são produtos fornecidos comercialmente, o que limita o número de usuários. 
Portanto, a divulgação da teoria emergente green criminology, está ligada à sua disponibilização em um maior número de acervos virtuais, possibilitando o conhecimento a novos pesquisadores, inclusive de distintas nacionalidades e geografias. O que permitirá que essa nova ferramenta possa ser percebida como instrumento preventivo de danos ambientais, enquanto referência para reflexões sobre os delitos, as leis e justiça ambiental, através de um novo paradigma de governança ambiental.

\section{Publicações científicas por tipologia}

O gráfico 1 apresenta, numérica e percentualmente, a distribuição da frequência das publicações de acordo com a classificação adotada pelo Portal de Periódicos da CAPES em artigo, book review, capítulo de livro, livro, entrada de referência (editorial), tese, recurso textual (editorial) e relatório. Os dados evidenciam que das oito classificações apresentadas artigo foi o documento com maior ocorrência, representando $46 \%$ (32 registros) das publicações relacionadas com a green criminology. Ele é seguido muito atrás pelos formatos book review (25\%) e capítulo de livro (14\%). Os registros de outras tipologias representaram menos de $15 \%$ da amostra.

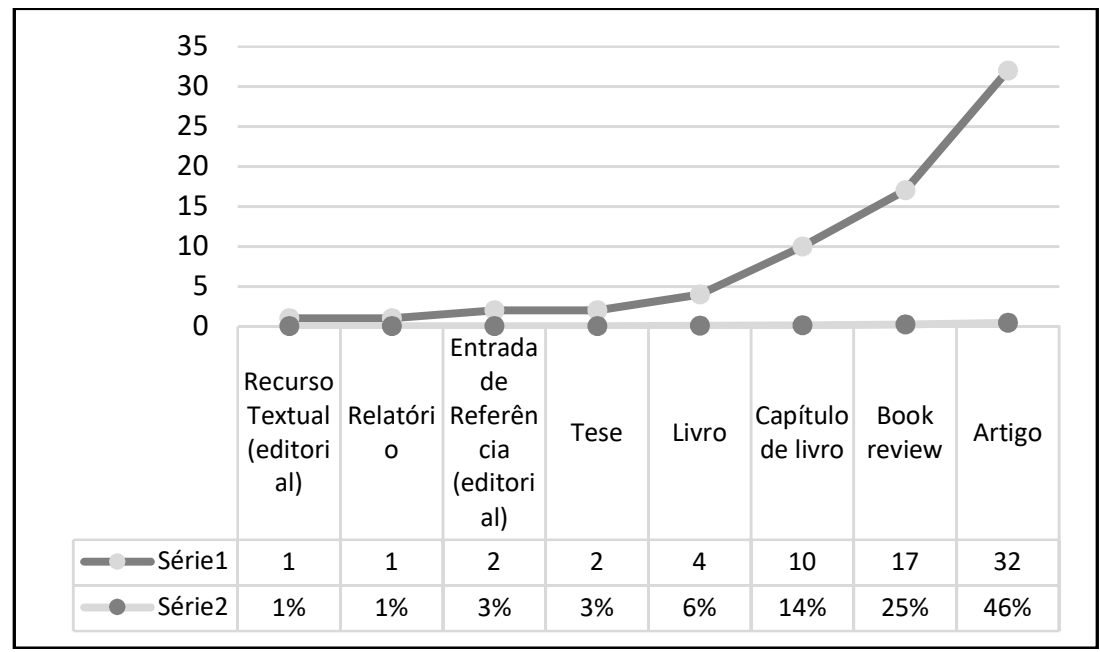

Gráfico 1: Frequência das publicações científicas por tipologia.

Os artigos científicos, disponíveis, em sua integralidade, apenas no idioma inglês, foram publicados em 18 periódicos indexados a múltiplas bases de dados, com fator de impacto consolidado pelo Journal Citation Reports (JCR). Assim, partindo do pressuposto de que a indexação é o pilar central que norteia o grau de credibilidade das pesquisas científicas, prediz-se que os artigos em análise passaram por critérios de aceitação rígidos (revisão por pares), conferindo qualidade, confiabilidade e originalidade ao estudo.

O fator de impacto enquanto critério avaliativo de fixação da revista, frente ao número médio de citações de artigos científicos, evidenciou que as publicações analisadas possuem representatividade na sua área. Assim, ainda que emergente, a teoria green criminology encontra-se publicada em periódicos com alto grau de confiabilidade científica e aderência direta na área da criminologia, e, portanto, adoção de princípios éticos, impactando significativamente a investigação da temática. 


\section{Autoria}

A identificação das autorias dos documentos possibilitou verificar a distribuição dos trabalhos realizados em autoria individual e coautoria, e ainda os pesquisadores que mais se destacaram em publicações. O inventário da amostra evidenciou que as publicações compreenderam 44 autores, sendo que 31 autores possuem uma única publicação e 13 concentram frequência múltipla, ou seja, detêm acima de dois trabalhos. Os dados demonstram que, embora, haja uma dispersão dos 69 documentos entre os 44 escritores, há uma concentração das pesquisas em 30\% destes. O gráfico 2 apresenta as publicações dos autores com frequência múltipla.

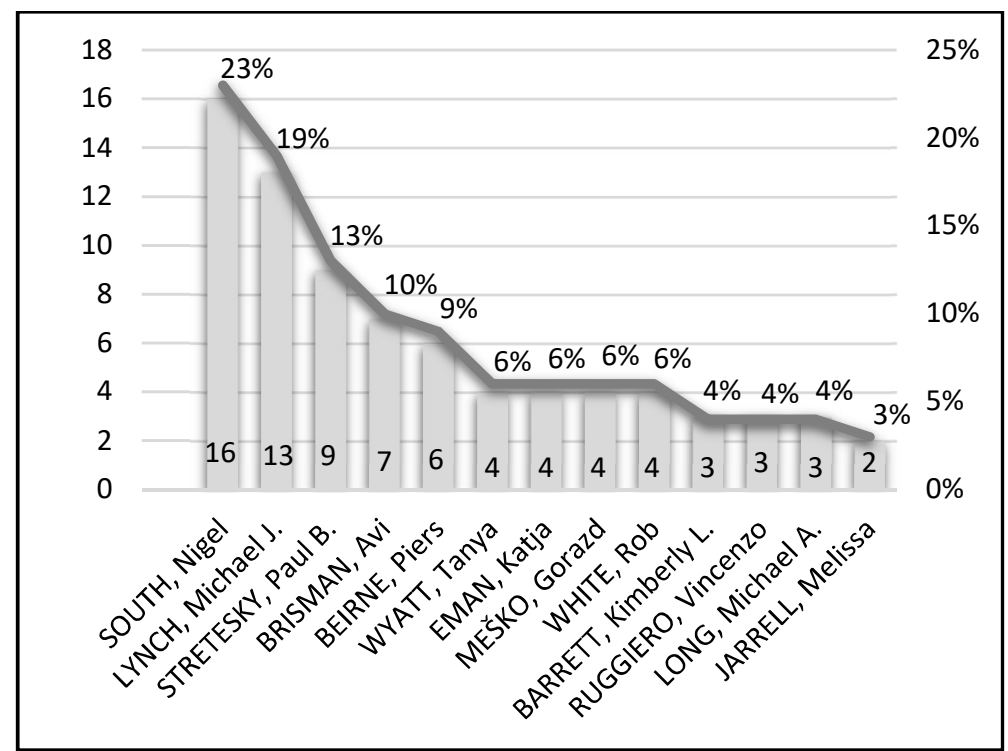

Gráfico 2: Autores com múltiplas publicações: quantidade e percentual em relação à amostra.

Os dados revelaram que os três autores com maior número de publicações, sozinhos, perfazem $55 \%$ dos documentos analisados: em primeiro, com 23\%, surge o inglês Nigel South; o precursor da green criminoly, Michael Lynch, ocupa o segundo lugar das publicações, com 19\% do total da amostra; em terceiro Paul B. Stretesky com percentual 13\% em relação a amostra (nove registros). Os pesquisadores South, Lynch e Stretesky são professores vinculados a departamentos de criminologia de universidades, bem como membros do International Green Criminology Working Group (Grupo Internacional de Trabalho sobre Criminologia Verde), o que demonstra aderência dos pesquisadores as publicações da amostra.

Os autores com maior percentual de publicações também caracterizam-se pela coautoria, ao privilegiarem a escrita de seus trabalhos com diversidade de autores: Nigel South (Avi Brisman, Bill McClanahan, Gorazd Meško, Hope Johnson, Piers Beirne, Reece Waltersd, Rob White, Tanya Wyatt e Vincenzo Ruggiero); Michael Lynch, possui um único artigo individual (Bruce A. Arrigo, Emily Fenwick, Kimberly L. Barrett, Lyndsay N. Boggess, Melissa Jarrell, Michael A. Long, Paul B. Stretesky); e Paul B. Stretesky (Emily Fenwick, Kimberly L. Barrett, Melissa Jarrell, Michael A. Long e Michael J. Lynch).

A pesquisa com pluralidade de autores indica uma tendência em se estabelecer parcerias entre os pesquisadores com o intuito de desenvolver pesquisas na temática estudada, permitindo o compartilhamento de informações, bem como o enriquecimento do estudo, através de percepções diversas 
do objeto de análise.

\section{Vínculo institucional dos pesquisadores}

Os 44 autores vinculam-se a 33 instituições, sendo 32 universidades e um centro internacional de pesquisa. Os dados evidenciaram uma não centralidade de autores, pois, $70 \%$ das instituições contemplam apenas um pesquisador, e, embora haja oito universidades com multiplicidade de autores, apenas a University of Maribor, localizada na Eslovênia, concentra geograficamente os estudos em green criminology, considerando que o país não detém outros pesquisadores do tema.

Observou-se que não há entre os autores nenhum pesquisador vinculado direta ou indiretamente a departamento da administração pública dos países. Essa realidade é preocupante frente ao desenvolvimento, implantação ou adoção de políticas públicas indiferentes a métodos que estudam os danos para preveni-los, pois não há como prevenir eficazmente o que não se conhece cientificamente.

\section{Espacialização das publicações}

Geograficamente os estudos abrangeram pesquisadores de 11 países, mas as publicações centramse em três, com um total de $64 \%$ da amostra, são eles Estados Unidos, Inglaterra e Austrália (Gráfico 3). Já os pesquisadores de múltiplas publicações localizam-se em apenas quatro das 11 nações, possuindo maior frequência os Estudos Unidos da América com 54\% dos desses autores.

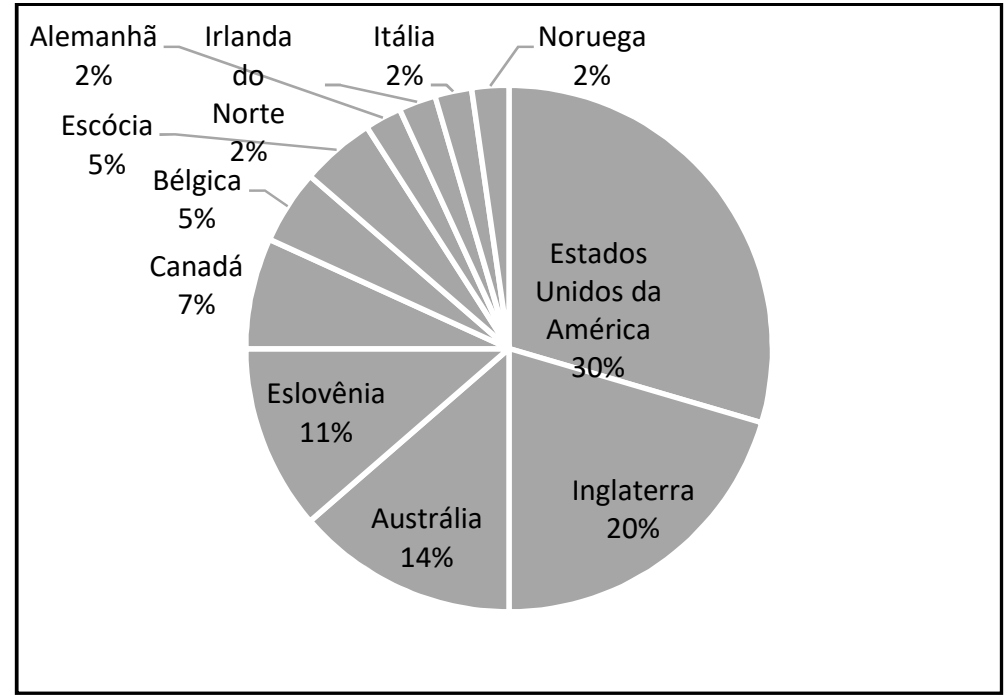

Gráfico 3: Ocorrência da autoria da amostra por países.

O gráfico 3 aponta para a existência de discussões da temática em três continentes: América (parte norte), Europa e Oceania. Os dados evidenciaram que a concentração das discussões e estudos localizaramse nos países desenvolvidos, especificamente Estados Unidos da América, Inglaterra, Austrália, Eslovênia, Canadá, Bélgica, Escócia, Alemanha, Irlanda do Norte, Itália e Noruega, denominados por Arrigui (1997) como países núcleos, demonstrando que a ausência do conhecimento da teoria emergente green criminology interliga-se a questões político-geográficas. 


\section{Cronologia das publicações}

Observando o gráfico 4, percebeu-se que as publicações virtuais dos estudos sobre a teoria green criminology iniciou no final do século XX, tendo como marco o ano de 1998. Essa informação evidencia que, da publicação precursora em 1990 nos Estados Unidos da América "The greening of criminology: a perspective on the 1990's", que marcou a green criminology, passaram-se sete anos até que a base de dado ProQuest LLCAll rights reserved registrasse a primeira divulgação das pesquisas sobre o tema: "A Green Field for Criminology? A Proposal for a Perspective". O artigo, publicado no periódico Theoretical Criminology, teve autoria do inglês Nigel South, o qual despontou na amostra com $23 \%$ dos documentos analisados, o primeiro em relação a outros escritores com múltiplas publicações.

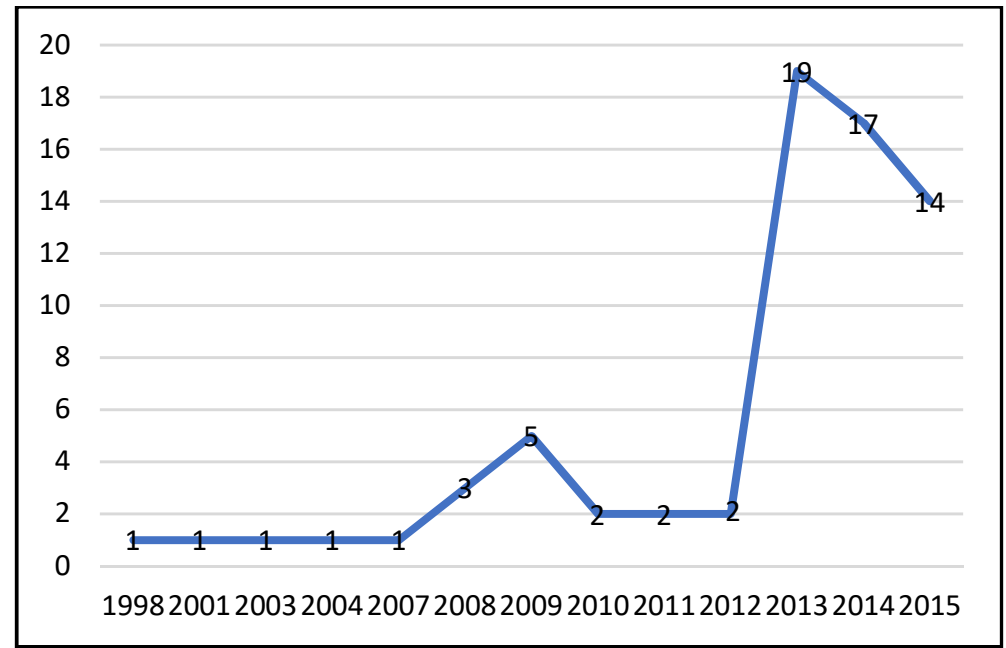

Gráfico 4: Cronologia anual das publicações da amostra.

Quanto a dinâmica temporal a ocorrência das publicações manteve-se estagnadas até 2007, passando por lacunas em cinco momentos: 1999, 2000, 2002, 2005 e 2006. Evidenciou-se ainda, que desde 2008 a temática vem evoluindo, embora seu progresso não seja linear, já que perpassou movimento de ascensão, especialmente em 2009 e 2013, este último representando o período mais produtivo em termos de publicações.

No entanto, apesar da ascensão dos documentos, em 2009, 2010, 2011 e 2012, o número de publicações acabou decrescendo. Contudo, o crescimento progressivo de publicações e referências associadas indicam um desenvolvimento de comunicação no domínio da investigação da green criminology durante os últimos oito anos.

\section{CONCLUSÕES}

As informações obtidas através da presente pesquisa exploratória permitiram um panorama do perfil das publicações no tocante à green criminology. A partir do construto adotado foi possível concluir que a literatura sobre o tema se tornou mais ampla e global nos últimos 18 anos. Na análise da linguagem todos os documentos foram publicados na íntegra apenas em Inglês, tendo sido disponibilizados em bases de dados diversas, o que possibilitou maior acessibilidade à pesquisadores.

O estudo também revelou que artigo científico foi a tipologia com maior número documentos, 
publicados em periódicos indexados em múltiplas bases de dados, portanto, as pesquisas se encontram publicadas em periódicos com alto grau de confiabilidade científica e aderência direta na área da criminologia, impactando significativamente a investigação da temática.

Os resultados apontaram que o número de autores é inferior ao total de documentos da amostra, concentrando às publicações em apenas $30 \%$. Nigel South, Michael Lynch e Paul Stretesky publicaram mais da metade da amostra, caracterizando-se pela escrita com multiplicidade de autores, demonstrando que os estudos possuem um perfil de diversidade das percepções da teoria green criminology.

Quanto a espacialização dos estudos Estados Unidos, Inglaterra e Austrália abrangeram $64 \%$ da amostra, demonstrando que inexiste publicações em três continentes, tendo concentração em uma minoria de países, sempre pertencentes ao grupo de nações núcleos. Assim, no continente Americano, os países integrantes da parte central e sul, considerados periféricos ou semiperiféricos, como o Brasil, não aparecem no inventário como pesquisadores do tema.

Conclui-se que há ausência de estudos em green criminology encontra limites nas questões políticasgeográficas o que inibe a diversidade de percepções espaciais sobre a temática, refletindo no amadurecimento das pesquisas em relação a teoria. Tal ausência também é prejudicial a realidade premente das ditas nações periféricas ou semiperiféricas que almejam seu crescimento econômico e, por conseguinte a exploração dos seus recursos ambientais, visto que a green criminology é uma ferramenta proativa na proteção e precaução ambiental.

\section{REFERÊNCIAS}

AGRA, C.. A criminologia: um arquipélago interdisciplinar. Porto: Universidade do Porto, 2012.

AMADO, F. A. T.. Direito ambiental esquematizado. 4 ed. Rio de Janeiro: Forense, 2013

ARRIGUI, G.. A ilusão do desenvolvimento. 6 ed. Petrópolis: Vozes, 1997.

BECK, U.. Sociedade de risco: rumo a uma outra modernidade. 2 ed. São Paulo: Editora 34, 2011

BISSCHOP, L.. Governance of the Illegal Trade in E-Waste and Tropical Timber: Case Studies on Transnational Environmental Crime. Farnham: Ashgate, 2015.

BRASIL. Lei n.6938 de 31 de agosto de 1981. Dispõe sobre a Política Nacional do Meio Ambiente, seus fins e mecanismos de formulação e aplicação, e dá outras providências. Brasília: DOU, 1981.

BRISMAN, A.; SOUTH, N.. A green-cultural criminology: an exploratory outline. Crime, Media, Culture, v.9, n.2, p.115135, 2013.

CASTRO, F.; HOGENBOOM, B.; BAUD, M.. Governança ambiental na América Latina: para uma agenda de pesquisa mais integrada. Ambiente \& Sociedade, São Paulo, v.14, n.2, p.1-13, 2011.

DIAS, V. V.; SCHULTZ, G.; SCHUSTER, M. S.; TALAMINI, E.; RÉVILLION, J. P.. O mercado de alimentos orgânicos: um panorama quantitativo e qualitativo das publicações internacionais. Ambiente \& Sociedade, São

Paulo, v.18, n.1, p.155-174, 2015. DOI: http://doi.org/10.1590/1809-4422ASOC841V1812015en

ELVAN, O. D.. Forest offences in 21st Century Turkey (with the example for the offender and trial period of illegal use of the forests in Istanbul). International Journal of Law, Crime and Justice, v.42, n.4, p.324-339, 2014. DOI: http://doi.org/10.1016/j.ijlcj.2014.04.002

FARIA, R.; AGRA, C.. A história epistemológica da criminologia. In: AGRA, C.. A Criminologia: um arquipélago interdisciplinar. Porto: Universidade do Porto Editorial, 2012.

FERREIRA, A. G. C.. Bibliometria na avaliação de periódicos científicos. DataGramaZero, v.11, n.3, p.A05, 2010.

FITZGERALD, A.; BARALT, L. B.. Media constructions of responsibility for the production and mitigation of environmental harms: the case of mercury-contaminated fish. Canadian Journal of Criminology and Criminal Justice, v.52, n.4, p.341-368, 2010.

HIKAL, W.. Criminologías especializadas. Revista Electrónica del Instituto Latinoamericano de Estudios en Ciencias Penales y Criminología, v.4, n.3, 2009.

HINOJOSA, T. D. G.. La explicación científica en criminologia: Derecho Penal y Criminología. Revista del Instituto de 
Ciencias Penales y Criminológicas, v.33, n.94, p.127-153, 2012.

IORIS, A. A. R.. O que é justiça ambiental?. Ambiente \& Sociedade, v.12, n.2, p.389-392, 2009.

JACOBI, P. R.; GIATTI, L. L.. A ambivalência do desenvolvimento e a busca de novas vias para a sustentabilidade. Ambiente \& Sociedade, v.18, n.3, 2015. DOI: http://doi.org/10.1590/18094422ASOCeditorialV1832015

LEITE, J. R. M.; SILVA, J. A. L.. Juridicidade do dano ambiental: gestão da zona costeira e aspectos da exploração do pré-sal pelo Brasil. Sequência, Florianópolis, n.65, p.305-328, 2012.

LYNCH, M. J.. The greening of criminology: a perspective on the 1990's. The Critical Criminologist, v.2, n.3, p.3-12, 1990.

LYNCH, M. J.; LONG, M. A.; BARRETT, K. L.; STRETESKY, P. B.. Is it a Crime to Produce Ecological Disorganization? Why Green Criminology and Political Economy Matter in the Analysis of Global Ecological Harms. The British Journal of Criminology, v.53, n.6, p.997-1016, 2013.

MILARÉ, É.. Direito do ambiente. 8 ed. São Paulo: Revista dos Tribunais, 2013.

PELLIZZARO, P. C.; HARDT, L. P. A.; HARDT, C.; HARDT, M.; SEHLI, D. A.. Gestão e manejo de áreas naturais protegidas: contexto internacional. Ambiente \& Sociedade, v.18, n.1, p.19-36, 2015.

PENTEADO FILHO, N. S.. Manual esquemático de criminologia. 2 ed. São Paulo: Saraiva, 2012.

PRIEUR, M.. Droit de l'Environment. 3 ed. Paris: Dalloz, 1996.

PUCCI, R. D.. Regulierungstechniken für Umweltdelikte und Restorative Justice. Revista da Faculdade de Direito, Universidade de São Paulo, São Paulo, v.108, p.531-541, 2013. DOI: http://doi.org/10.11606/issn.23188235.v108i0p531-541

SÁNCHEZ, L. E.. Avaliação de impacto ambiental: conceitos e métodos. 2 ed. São Paulo: Oficina de textos, 2013.

SOUTH, N.. Green criminology: Reflections, corrections, horizons. International Journal for Crime, Justice and Social Democracy, v.3, n.2, p.5-20, 2014.
SOUTH, N.; BRISMAN, A.. Routledge International Handbook of Green Criminology. New York: Routledge, 2013a.

SOUTH, N.; BRISMAN, A.; BEIRNE, P.. A guide to a green criminology. In: SOUTH, N.; BRISMAN, A.. New York: Routledge, 2013b.

SOUTH, N.; BRISMAN, A.; MCCLANAHAN, B.. Green Criminology. Oxford: Universidade de Oxford, 2014b. DOI: http://doi.org/10.1093/OBO/9780195396607-0161

SOUTH, N.; WHITE, R.. The antecedents and emergence of a 'Green' criminology. In: AGNEW, R.. Annual meeting presidential papers: selected papers from the presidential panels: expanding the core: neglected crimes, groups, causes and policy approaches. Atlanta: American Society of Criminology, 2014a.

VIVEIROS, E. P.; MIRANDA, M. G.; NOVAS, A. M. P.; AVELAR, K. E. S.. Por uma nova ética ambiental. Engenharia Sanitária e Ambiental, v.20, n.3, p.331-336, 2015. DOI: http://doi.org/10.1590/S1413-41522015020000114401

WHITE, R.. Crimes against nature: environmental criminology and ecological justice. Nova York: Rutledge, 2013.

WHITE, R.. Environmental Crime in Global Context: Exploring the Theoretical and Empirical Complexities. Current Issues in Criminal Justice, v.16, n.3, p.271-285, 2005.

WHITE, R.. Environmental issues and the criminological imagination. Theoretical Criminology, v.7, n.4, p.483-506, 2003.

WORTLEY, R.; MAZEROLLE, L.. Environmental criminology and crime analysis. New York: Routledge, 2011.

WYATT, T.; BEIRNE, P.; SOUTH, N.. Guest editors' introduction: green criminology matters. International Journal for Crime, Justice and Social Democracy, v.3, n.2, p.1-4, 2014.

ZHOURI, A.. Justiça ambiental, diversidade cultural e accountability: desafios para a governança ambiental. Revista Brasileira de Ciências Sociais, v.23, n.68, p.97-107, 2008. 